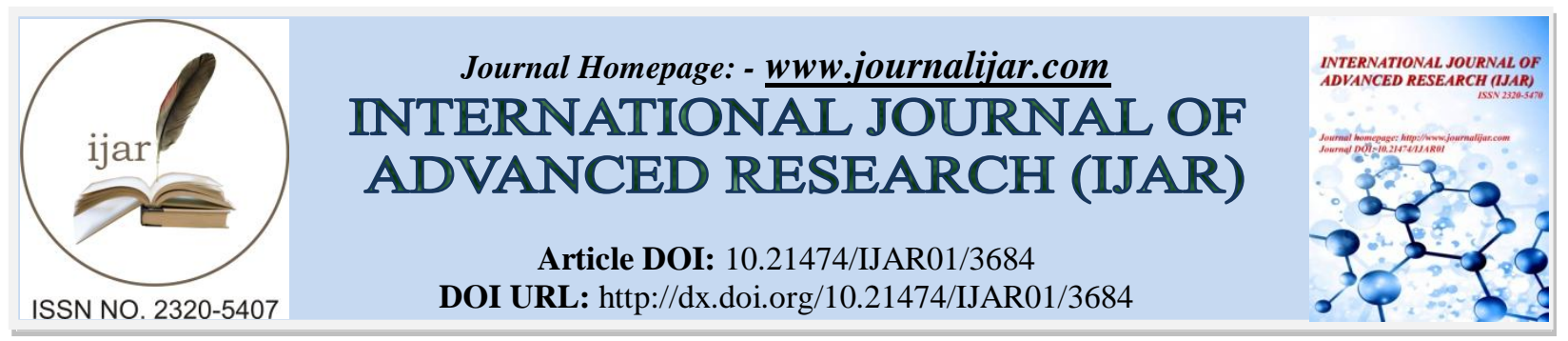

RESEARCH ARTICLE

\title{
STEREOMICROSCOPIC EVALUATION OF DENTINAL DAMAGE CAUSED BY K-FILES, PROTAPER UNIVERSAL, NEONITI A1 AND iRaCe FILES-AN IN VITRO STUDY
}

Dr. Arun Paul, Dr. Nithin Suvarna, Dr. K. Harish S. Shetty and Dr. Mohd. Nooh Khazia.

\section{Manuscript Info}

(.........................

Manuscript History

Received: 12 January 2017

Final Accepted: 10 February 2017

Published: March 2017

Key words:-

dentinal defects, cracks, rotary instruments, Neoniti A1, iRaCe, ProTaper Universal, Stainless steel Kfiles
Abstract

Aim: To compare the dentinal damage induced by stainless steel hand and rotary nickel-titanium instruments using $\mathrm{K}$ files, ProTaper Universal, Neoniti A1 and iRaCe files. Materials and Methods: Sixty single rooted premolars were collected and randomly divided into four groups of 15 teeth each. Group 1- Stainless steel K Files, group 2ProTaper Universal, group 3- Neoniti A1 file and group 4 - iRaCe rotary instruments. Cleaning and shaping was done with the respective files. The roots were then cut horizontally at $3 \mathrm{~mm}, 6 \mathrm{~mm}$ and $9 \mathrm{~mm}$ from apex and were examined under stereomicroscope. The sections were checked for dentinal defects. Statistical analysis: Groups were analysed with the Fishers exact test. Results: It was found that all instruments examined caused dentinal defects with maximum defects in the apical third. Neoniti A1 file showed least number of dentinal defects compared to other file systems. Conclusion: The present study revealed that all the instruments could result in an increased chance for dentinal defects.

Copy Right, IJAR, 2017,. All rights reserved.

\section{Introduction:-}

The main objective of endodontics is a three dimensional seal of the root canal system. There are various steps in root canal treatment and each step has its importance in the success of the treatment. The biomechanical preparation is one of the steps in the root canal treatment for removal of bacteria and debris from the root canal to receive an obturating material. ${ }^{1,2,3}$

Traditionally, the shaping of the root canal was achieved by the use of stainless steel hand files. ${ }^{4}$ Stainless steel root canal instruments clean the canal superficially and can create canal aberrations such as ledges, zips, and elbows. ${ }^{5}$ To eliminate these shortcomings of stainless steel instruments, nickel titanium(NiTi) instruments have been introduced.

It offers many advantages over conventional files. They are flexible (Walia et al. 1988), have increased cutting efficiency (Kazemi et al. 1996) and have improved time efficiency (Ferraz et al. 2001). Furthermore, Ni-Ti instruments maintain the original canal shape during preparation. ${ }^{4}$ 
ProTaper Universal (DENTSPLY Tulsa Dental Specialties) utilized multiple tapers of an increasing or decreasing percentage on a single file. This revolutionary, progressively tapered design limits each file's cutting action to a specific region of the canal. ${ }^{6}$

Recently Neoniti A1, a single file nickel titanium (NiTi) has been introduced which completes the canal preparation with only one instrument, this file system is made by the EDM (Electric Discharge Machining) process which is responsible for the unique behavior of the file ${ }^{7}$ which is claimed to relieve stress on the instrument because of its peculiar cutting action requiring even lesser time than rotary full-sequence systems. ${ }^{8}$ It is assumed that this movement reduces the risk of cyclic fatigue caused by tension and compression.

iRaCe $(\mathrm{FKG})$ provides a quick, safe and effective protocol for preparation of curved root canals. These recently introduced NiTi rotary files have the same design features as RaCe files. The working part has alternating cutting edges. This design avoids "screwing-in" effect and allows better control of the instrument's progression. ${ }^{9}$

Rotary files have increasing taper design that increases the cutting efficiency and relatively removes more dentin compared to other systems which leads to formation of more complete and incomplete dentinal cracks. ${ }^{10}$ Vertical root fractures, which is one common complication associated with mechanical canal preparation ${ }^{11}$, initiated from this dentinal crack (Wilcox et al. 1997), can lead to extraction.

A vertical root fracture is a longitudinally oriented fracture of the root, extending throughout the entire thickness of dentin from the root canal to the periodontium. It may be initiated in the crown or at the root apex or in some cases, along the root between these two points. ${ }^{12}$

Dentinal microcracks can occur during tooth extraction and tooth-sectioning procedures, and pre-existing defects may not be detected using root sectioning and microscopic observation techniques. ${ }^{13}$ A crucial goal in endodontic research is to overcome the potential problem of dentinal microcrack formation during instrumentation with rotary or reciprocating instruments. ${ }^{13}$ The purpose of this study is to evaluate dentinal defects caused by different NiTi file systems and $\mathrm{K}$ files.

\section{Material and Methods:-}

Sixty single rooted premolars were collected, cleaned with periodontal scaler and stored in purified water. Teeth with curved roots, calcified canals, developmental anomalies or extra canals were discarded. The coronal portions of all teeth were removed with diamond disk with water cooling leaving roots of $15 \mathrm{~mm}$ in length. All the root surfaces were observed with stereomicroscope under $24 x$ to rule out preexisting cracks or any craze lines.

Apical patency was checked using a 10 no. K file. Working length was determined by leaving 10 no. $\mathrm{K}$ file in the canal so that it was just visible at the apical foramen and from that length $0.5 \mathrm{~mm}$ was subtracted. The specimens were divided into 4 groups each group containing 15 specimens each.

Group 1- K Files stainless steel files (Mani)

Group 2- ProTaper Universal (DENTSPLY Maillefer )

Group 3- Neoniti A1 (NEOLIX, FRANCE)

Group 4- iRaCe (FKG Swiss endo)

In all the groups each canal was irrigated with $3 \%$ sodium hypochlorite and saline alternatively. Along with RCPrep (EDTA 15\% and urea peroxide 10\%) used between each sequential instrument in canal preparation.

Hand file group was prepared using stainless steel K files up to apical size 25 at the working length and step-back technique was used up to 40 no. K file.

In the ProTaper Universal group, the following sequence was used for canal preparation at $300 \mathrm{rpm}$ using a crown down technique. Sx file was used for coronal enlargement and S1, S2, F1 and F2 corresponding to apical size 25 used at working length.

In the Neoniti A1 (25/0.08) file group, the file was taken to the middle third using 3 or 4 circumferential brushing actions followed by taking it to the working length using a pecking motion at $300 \mathrm{rpm}$. 
In the iRaCe group, the file $\mathrm{R} 1$ in rotation was introduced into the canal and reached up to working length with long back and forth strokes and shaping of the canal was finished with R2(25/.04) up to working length. These files were used at $600 \mathrm{rpm}$.

For efficient cleaning of the canals EndoActivator (Dentsply Tulsa Dental) was used in all the groups, with no.25 tip for 30 seconds by agitating the solution vigorously. ${ }^{14}$

\section{Examination of roots:-}

After the biomechanical preparation, roots were sectioned from $3 \mathrm{~mm}, 6 \mathrm{~mm}$ and $9 \mathrm{~mm}$ from the apex using a diamond disk under water cooling. Digital images of all the section were captured using a $24 x$ stereomicroscope by using a digital camera (Olympus, Tokyo, Japan). Specimens were checked for dentinal defects by two examiners. Defects were classified using Wilcox et al. classification ${ }^{15}$ with modification.

Defects were classified as 'no defect', 'fracture' and 'all other defects'.

"No defect" was root dentine without any lines or cracks, neither the external surface nor the internal root canal wall had no defects.

"Fracture" was the teeth with crack that was extending from the root canal space to the outer root surface (Figure 1).

"Other defects" were other cracks that did not extend from the root canal to the outer root surface. This includes the internal and external craze lines and partial cracks.

"Internal craze lines" included cracks extending from the canal lumen wall into the dentin without reaching the root surface; however, "external craze lines" were defined as cracks extending from the root surface into dentin without reaching the canal lumen.

Samples were considered defective if at least one of the three sections showed any defect. Data were collected and statistical analysis was done.

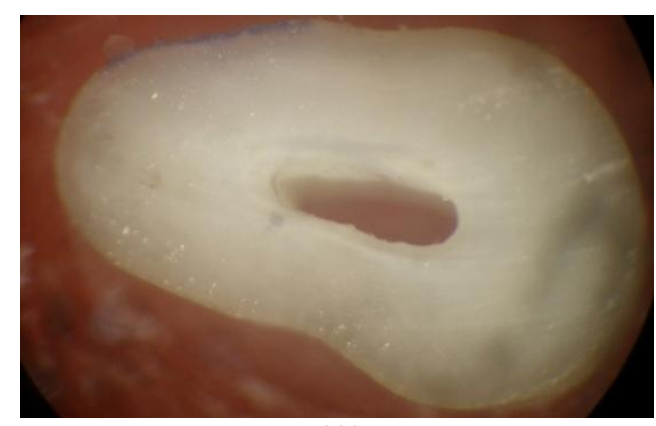

(A)

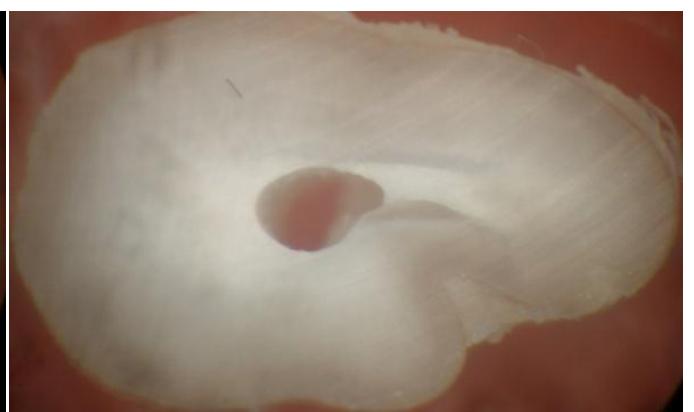

(B)

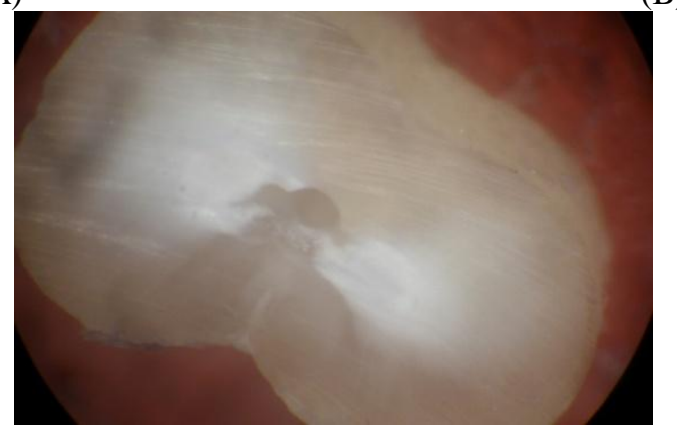

(C)

Figure 1:- (A) No defect (B) Partial Crack

(C) External Craze line

\section{Statistical analysis:-}

The data was analysed using statistical software SPSS (SPSS Inc., Chicago). Fisher's exact test was used to determine statistically significant difference in the appearance of defected roots between the experimental groups. 
Fisher's exact test was also performed to determine the defects at different horizontal sections in each group. The level of significance was set at $P<0.05$.

\section{Results:-}

Table 1 shows the number and percentage of cracks in each sections and the total number of defective samples. Figure 2 is a bar chart representing the percentage of defects in each group. Neoniti A1 group showed lowest defect (1/15) followed by ProTaper Universal and K files which showed same number of defects (3/15). iRaCe group showed maximum number of defects (4/15). Statistical significant difference was seen between Neoniti A1 group and iRaCe group $(\mathrm{P}<0.05)$. No significant difference was found between other groups $(\mathrm{P}>005)$. Only in the middle section, iRaCe and K files produced significantly more defects than ProTaper Universal and Neoniti A1 ( $<<0.05)$.

Table 1:- Number and percentage of cracks.

\begin{tabular}{|l|c|c|c|c|c|c|c|c|}
\hline & \multicolumn{2}{|c|}{ Group 1 } & \multicolumn{2}{c|}{ Group 2 } & \multicolumn{2}{c|}{ Group 3 } & \multicolumn{2}{c|}{ Group 4 } \\
\cline { 2 - 9 } & Number & $\%$ & Number & $\%$ & Number & $\%$ & Number & $\%$ \\
\hline Apical & 0 & $0 \%$ & 0 & $0 \%$ & 1 & $6.7 \%$ & 1 & $6.7 \%$ \\
\hline Middle & 3 & $20 \%$ & 1 & $6.7 \%$ & 0 & $0 \%$ & 4 & $26.7 \%$ \\
\hline Coronal & 0 & $0 \%$ & 2 & $13.3 \%$ & 1 & $6.7 \%$ & 0 & $0 \%$ \\
\hline Total & 3 & $20 \%$ & 3 & $20 \%$ & 1 & $6.7 \%$ & 4 & $26.7 \%$ \\
\hline
\end{tabular}

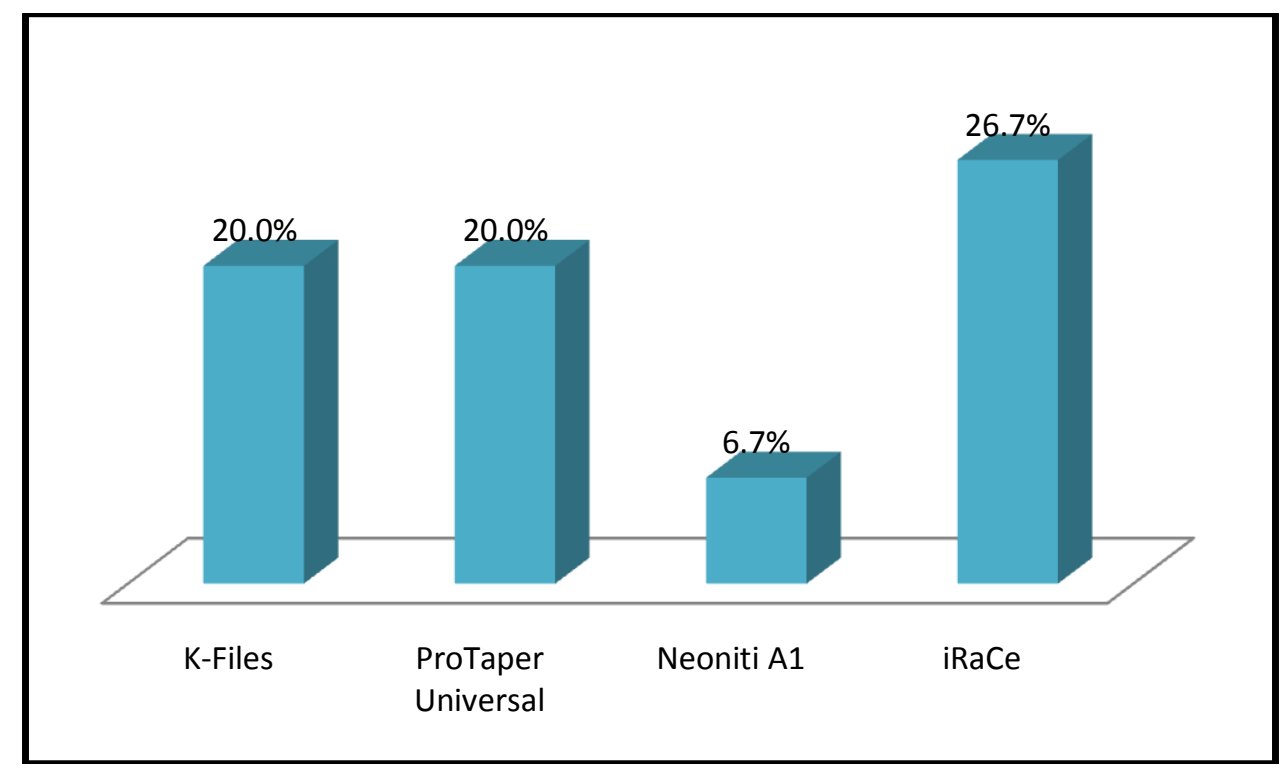

Figure 2:- Percentage of defects.

\section{Discussion:-}

NiTi instruments are used in rotational motion and rotational force is applied to root canal walls. This can create dentinal defects in root dentin. ${ }^{16}$ The aim of the present study was to detect the dentinal damage in the form of cracks and craze lines caused by K files and NiTi instruments.

In our study, we selected premolars because these teeth are probably more prone for forces of instrumentation. These teeth have got smaller dimensions and thin dentinal walls. If large tapered files cannot induce cracks in premolar, it is unlikely that rotary files induce cracks in other teeth. ${ }^{17}$

Only partial cracks were observed in this study, which indicates that fractures do not occur immediately after root canal preparation. In a study by Bier et al. ${ }^{18}$ the samples prepared with either hand or rotary instruments did not show any complete fracture. However, overtime these dentinal defects like craze lines or incomplete cracks may turn into fractures. But it has a potential effect on root fracture that makes these defects clinically significant. ${ }^{19}$ 
Rotary files cause more number of defects may be attributed to various reasons: Tip design, cross-section geometry, constant or variable taper, pitch and flute form. ${ }^{16,18,20,21,22}$ Crown down technique used in the canal preparation can also be considered as a contributor in the formation of dentinal cracks. ${ }^{21,21,23}$

In this study K file group as well as ProTaper Universal group showed dentinal defects (20\%). In a study by Dilek et al. ${ }^{19}$ all instruments including hand files showed dentinal defects. Though all the teeth selected in this study were having straight canals apical foramen is located eccentrically in 68 to $80 \%$ of the teeth. ${ }^{24}$ This indicates that even in straight roots canals are not straight and can curve apically. In fact all the roots have some degree of curvature. ${ }^{25}$ Stainless steel files are stiffer than NiTi files and this could be the reason why the K file group showed more defects. ${ }^{26}$ This is in contradiction to other studies which showed least number or no defects in the hand file group. ${ }^{18,27,28}$ This may be due to the fact that hand files removed less amount of dentin because of the less taper of the hand files. ${ }^{18,20}$

ProTaper Universal files caused significantly more cracks. Finishing files of ProTaper Universal files has got more taper. This may cause the dentinal cracks by generating increased stress on the dentinal walls as compared to other rotary system. ${ }^{29}$ These files have got more active rotating movement that may result in that may result in high levels of stress concentrations in root canal walls that may result in crack formation. ${ }^{30}$

Neoniti A1 file used in this study showed least number of defects. A literature search did not reveal any previous studies regarding the effect of this file system on root dentin. These files are made by EDM (Electric Discharge Machining) process offers unique features such as progressive flexibility, sharp cutting edges and built in abrasive properties. The relatively high flexibility of Neoniti A1 file may be the reason for the less number of cracks in this study. ${ }^{31}$ Moreover, Neoniti A1 is a single file system. Only one file is required for the complete shaping of the canal and this may also contributes to the less number of defects. ${ }^{31}$ As the EDM technology is a newly introduced method for the manufacture of files, future studies with more focus on dentinal defects in root dentine are therefore suggested.

Among the groups iRaCe showed maximum number of defects (26.7\%). The RaCe files have a sharp cutting edge with convex triangular cross-section. They have asymmetrical longitudinal design. A set of cutting edge alternates with the second set pitched at a different angle leading to two different cutting edges on the same file. This could cause stress concentration at specific points rather than distribute it along the entire length of file. ${ }^{32}$ This concentration of stresses could have led to significantly more cracks seen with this system. ${ }^{26}$ Moreover these files were used at a higher rpm (600). This can be the other reason for the higher number of cracks with these files. ${ }^{18,23,33,34}$ On the contrary Peters et al. (2014) and Ceyhanli et al (2015) reported that high rotational speeds enhanced cutting efficiency and decreased defect formation.

\section{Limitations:-}

1. Use of different speed settings for each rotary system.

2. Simulation of periodontal ligament was not done in the present study. Capar et al ${ }^{31}$ stated that simulation of the periodontal ligament is necessary for investigating the influence of forces on formation of crack or fracture strength. Moreover, the periodontal ligament has viscoelastic property. It plays a vital role in stress dissipation due to application of load on the teeth.

3. Pre-existing defects due to excessive force during tooth extraction or during sectioning of the tooth that could not be evaluated.

\section{Conclusions:-}

Even though this in vitro study did not reflect the clinical settings, within the limitations of this study it can be concluded that all the instruments examined caused dentinal defects. More defects were observed in the apical one third followed by middle one third. Neoniti A1 file showed least number of dentinal defects compared to other file systems. More studies using techniques such as micro CT is suggested for further evaluation. 


\section{References:-}

1. Peters OA. Current challenges and concepts in the preparation of root canal systems: a review. Journal of endodontics. 2004 Aug 31;30(8):559-67.

2. Bergmans L, Van Cleynenbreugel J, Beullens M, Wevers M, Van Meerbeek B, Lambrechts P. Smooth flexible versus active tapered shaft design using NiTi rotary instruments. International Endodontic Journal. 2002 Oct 1;35(10):820-8.

3. Schilder H. Cleaning and shaping the root canal. Dent Clin North Am. 1974;18:269-96.

4. Yared G. Canal preparation using only one Ni-Ti rotary instrument: preliminary observations. International endodontic journal. 2008 Apr 1;41(4):339-44.

5. Singh S, Nigam N. Comparative evaluation of surface characteristics of dentinal walls with and without using plastic finishing file. Journal of Conservative Dentistry. 2010 Apr 1;13(2):89.

6. Ruddle CJ, Machtou P, West JD. The shaping movement 5th generation technology. Dent Today. 2013 Apr;32(4):94.

7. Gupta R, Dhingra A, Aggarwal N, Yadav V. A new approach to single file endodontics: Neoniti rotary file system. Int J Advances In Case Reports. 2015;2(16):1030-2.

8. Bürklein S, Hinschitza K, Dammaschke T, Schäfer E. Shaping ability and cleaning effectiveness of two single-file systems in severely curved root canals of extracted teeth: Reciproc and WaveOne versus Mtwo and ProTaper. International Endodontic Journal. 2012 May 1;45(5):449-61.

9. Saber SE, Nagy MM, Schäfer E. Comparative evaluation of the shaping ability of ProTaper Next, iRaCe and Hyflex CM rotary NiTi files in severely curved root canals. International endodontic journal. 2015 Feb 1;48(2):131-6.

10. Bergmans L, Van Cleynenbreugel J, Beullens M, Wevers M, Van Meerbeek B, Lambrechts P. Smooth flexible versus active tapered shaft design using NiTi rotary instruments. International Endodontic Journal. 2002 Oct 1;35(10):820-8.

11. Tamse A, Fuss Z, Lustig J, Kaplavi J. An evaluation of endodontically treated vertically fractured teeth. Journal of endodontics. $1999 \mathrm{Jul}$ 1;25(7):506-8.

12. Pitts DL, Natkin E. Diagnosis and treatment of vertical root fractures. Journal of endodontics. 1983 Aug 1;9(8):338-46.

13. Ceyhanli KT, Erdilek N, Tatar I, Celik D. Comparison of ProTaper, RaCe and Safesider instruments in the induction of dentinal microcracks: a micro-CT study. International endodontic journal. $2015 \mathrm{Jul} 1$.

14. Kumar VR, Bahuguna N, Manan R. Comparison of efficacy of various root canal irrigation systems in removal of smear layer generated at apical third: An SEM study. Journal of conservative dentistry: JCD. 2015 May;18(3):252.

15. Wilcox LR, Roskelley C, Sutton T. The relationship of root canal enlargement to finger-spreader induced vertical root fracture. Journal of Endodontics. 1997 Aug 1;23(8):533-4.

16. Yoldas O, Yilmaz S, Atakan G, Kuden C, Kasan Z. Dentinal microcrack formation during root canal preparations by different NiTi rotary instruments and the self-adjusting file. Journal of endodontics. 2012 Feb 29;38(2):232-5.

17. Ashraf F, Shankarappa P, Misra A, Sawhney A, Sridevi N, Singh A. A Stereomicroscopic Evaluation of Dentinal Cracks at Different Instrumentation Lengths by Using Different Rotary Files (ProTaper Universal, ProTaper Next, and HyFlex CM): An Ex Vivo Study. Scientifica. 2016 Jun 29;2016.

18. Bier CA, Shemesh H, Tanomaru-Filho M, Wesselink PR, Wu MK. The ability of different nickel-titanium rotary instruments to induce dentinal damage during canal preparation. Journal of Endodontics. 2009 Feb 28;35(2):236-8.

19. Helvacioglu-Yigit D, Aydemir S, Yilmaz A. Evaluation of dentinal defect formation after root canal preparation with two reciprocating systems and hand instruments: an in vitro study. Biotechnology \& Biotechnological Equipment. 2015 Mar 4;29(2):368-73.

20. Shemesh H, Bier CA, Wu MK, Tanomaru-Filho M, Wesselink PR. The effects of canal preparation and filling on the incidence of dentinal defects. International Endodontic Journal. 2009 Mar 1;42(3):208-13.

21. Adorno CG, Yoshioka T, Suda H. Crack initiation on the apical root surface caused by three different nickeltitanium rotary files at different working lengths. Journal of endodontics. 2011 Apr 30;37(4):522-5. 
22. Thompson SA. An overview of nickel-titanium alloys used in dentistry. International endodontic journal. 2000 Jul 1;33(4):297-310.

23. Adorno CG, Yoshioka T, Suda $\mathrm{H}$. The effect of working length and root canal preparation technique on crack development in the apical root canal wall. International endodontic journal. 2010 Apr 1;43(4):321-7.

24. Kuttler Y. Microscopic investigation of root apexes. The Journal of the American Dental Association. 1955 May 1;50(5):544-52.

25. Ingle JI. Ingle's Endodontics 6. 6th ed. Hamilton, Ontario: BC Decker; 2008. 938p

26. Devale MR, Mahesh MC, Bhandary S. Effect of Instrumentation Length and Instrumentation Systems: Hand Versus Rotary Files on Apical Crack Formation-An In vitro Study.

27. Sathorn C, Palamara JE, Messer HH. A comparison of the effects of two canal preparation techniques on root fracture susceptibility and fracture pattern. Journal of Endodontics. 2005 Apr 30;31(4):283-7.

28. Liu R, Kaiwar A, Shemesh H, Wesselink PR, Hou B, Wu MK. Incidence of apical root cracks and apical dentinal detachments after canal preparation with hand and rotary files at different instrumentation lengths. Journal of endodontics. 2013 Jan 31;39(1):129-32.

29. Gianluca G. The K3 rotary nickel titanium instrument system. Endodontic Topics. 2005 Mar 1;10(1):179-82.

30. West JD. Introduction of a new rotary endodontic system: progressively tapering files. Dentistry today. 2001 May;20(5):50-2.

31. Capar ID, Arslan H, Akcay M, Uysal B. Effects of ProTaper Universal, ProTaper Next, and HyFlex instruments on crack formation in dentin. Journal of endodontics. 2014 Sep 30;40(9):1482-4.

32. McSpadden JT. Mastering endodontic instrumentation. Chattanooga, TN: Cloud land. Institute, 2007:51-52.

33. Milani AS, Froughreyhani M, Rahimi S, Jafarabadi MA, Paksefat S. The effect of root canal preparation on the development of dentin cracks. Iranian endodontic journal. 2012 Oct 20;7(4):177-82.

34. Jain A, Bhadoria K, Choudhary B,Patidar N. Comparison of Dentinal Defects induced by Hand Files, Multiple, and Single Rotary Files: A Stereomicroscopic Study. January 2017 World Journal of Dentistry 8(1):45-48. 